\title{
Characteristics, Biological Properties and Analytical Methods of Ursolic Acid: A Review
}

\section{Andressa Maria Pironi, Patricia Rocha de Araújo, Mariza Aires Fernandes, Hérida Regina Nunes Salgado \& Marlus Chorilli}

To cite this article: Andressa Maria Pironi, Patricia Rocha de Araújo, Mariza Aires Fernandes, Hérida Regina Nunes Salgado \& Marlus Chorilli (2018) Characteristics, Biological Properties and Analytical Methods of Ursolic Acid: A Review, Critical Reviews in Analytical Chemistry, 48:1, 86-93, DOI: $10.1080 / 10408347.2017 .1390425$

To link to this article: https://doi.org/10.1080/10408347.2017.1390425

Accepted author version posted online: 17

Oct 2017.

Published online: 20 Dec 2017.

Submit your article to this journal $\widetilde{ }$

Џ Article views: 207

Citing articles: 3 View citing articles 


\title{
Characteristics, Biological Properties and Analytical Methods of Ursolic Acid: A Review
}

\author{
Andressa Maria Pironi (D), Patricia Rocha de Araújo (D), Mariza Aires Fernandes, Hérida Regina Nunes Salgado (D), \\ and Marlus Chorilli
}

Departament of Drugs and Medicines, São Paulo State University (UNESP), School of Pharmaceutical Sciences, Araraquara, São Paulo, Brasil

\begin{abstract}
Ursolic acid (UA) is a naturally occurring triterpenoid which is a promising candidate for the development of new therapeutic approaches and for the prevention and treatment of several diseases owing to its pharmacological importance. However, its low solubility in aqueous medium affects its therapeutic application. Several strategies have been used to overcome this obstacle. In this study, the incorporation of UA in to different drug delivery systems was found to be highly efficient. In addition, important investigations were performed about methods for qualitative and quantitative analyses of UA in various raw materials, including plants, biological fluids, and drug delivery systems, were investigated. Most recently high performance liquid chromatography coupled with various detectors, gas chromatographymass spectrometry and capillary electrophoresis were used for this purpose. Thus, this review was performed to evaluate the biological effects of UA demonstrated thus far as well as the currently used, delivery systems and analytical methods.
\end{abstract}

\section{KEYWORDS}

Ursolic acid; biological

effects; drug delivery

systems; analytical methods

\section{Introduction}

Ursolic acid is a pentacyclic triterpenoid $\left(\mathrm{C}_{30} \mathrm{H}_{48} \mathrm{O}_{3}\right.$; Figure 1) of molecular weight with a $456.68 \mathrm{~g} / \mathrm{mol}$ and melting point of $283-$ $285^{\circ} \mathrm{C}$, which belongs to class of $\mathrm{C}_{30}$ isoprenoid compounds. These compounds are widely distributed in nature; therefore, UA can be isolated from various plants, such as Calluna vulgaris (heather), Rosmarinus officinalis (rosemary), Callendula officinalis (marigold), Melaleuca leucadendron (melaleuca), Malus domestica (apple), Origanum vulgare (oregano), Salvia officinalis (sage), Origanum majorana (marjoram), Lavandula angustifolia (lavender flowers), Thymus vulgaris (thyme) and Eucalyptus (eucalyptus). ${ }^{[1,2]}$ The presence of UA in most medicinal herbs and fruits makes it a component of human diet. ${ }^{[3]}$

The biosynthesis of UA and other isoprenoid compounds found in plant tissues, occurs from the cyclization of squalene into (3S)-oxidosqualene, which can produce over 80 different carbon skeletons ${ }^{[4]}$ through the activity of oxidosqualene cyclase enzymes that realize the carbocation rearrangements responsible for this biological variety. The common precursor (3S)-oxidosqualene is converted into the dammarenyl ring that undergoes ring expansion and other cyclization reactions to form the characteristic fifth ring present in lupeol, $\alpha$-amyrin, and $\beta$-amyrin skeletons. The $\alpha$-amyrin represents the UA skeleton, whereas its $\mathrm{C} 30$ isomer, $\beta$-amyrin is the representative skeleton of the oleanolic acid (OA). ${ }^{[5]}$

The crystalline solid compound, chemically known as $3 \beta$ hydroxy-urs-12-en-28-oic acid, has been used for a long time in folk medicine for its therapeutic activities. ${ }^{[2]}$ Recently, the search for biologically active substances from natural sources has increased interest in its investigation.
Studies indicate that UA has various pharmacological effects, including anti-inflammatory, hepatoprotective, antitumor, cardioprotective, neuroprotective, antimicrobial, antihyperlipidemic, anti-diabetic, antifungal, antiviral and trypanocidal. $^{[6]}$

However, it is classified as a class IV drug in the Biopharmaceutics Classification System owing to its limited pharmacological effects due to low solubility in water and difficulty in permeating biological membranes. ${ }^{[7]}$ Thus, new approaches have been introduced to enhance the biopharmaceutical properties of this compound, particularly drug delivery technologies. Several UA delivery systems have been used successfully, such as nanoemulsions, ${ }^{[8]}$ mesoporous silica nanoparticles, ${ }^{[9]}$ solid lipid nanoparticles, ${ }^{[10]}$ liposomes, ${ }^{[11]}$ niossomal gels ${ }^{[12]}$ and solid dispersions. ${ }^{[13]}$

Owing to its numerous important pharmacological effects, analytical methods for UA being increasingly researched. A few studies have reported methods developed for UA analysis. In this study, we reviewed the biological effects of UA and the delivery systems and analytical methods used.

The Scopus, Science Direct and PubMed databases were used for the review. The main descriptors used were as follows: "ursolic acid" in combination with "biological effects", "antiinflammatory", "antitumor", "drug delivery system", "analytical methods", "HPLC", "GC", "MS", "UPLC", and "electrophoresis".

\section{Pharmacological aspects of ursolic acid}

\section{Anti-inflammatory effect}

Nuclear factor kappa B (NF-k $\beta$ ) is major cell signaling pathway responsible for the regulation of inflammatory 


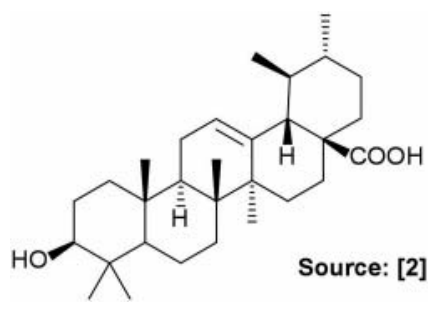

Figure 1. Chemical structure of ursolic acid.

genes expression. ${ }^{[14]}$ The evaluation of anti-inflammatory effects of UA by exposing BALB/c mice to ovalbumin for asthma induction revealed that UA inhibits NF- $\kappa$ B, and thus can be used in the treatment of asthma. ${ }^{[15]}$ Checker et al. ${ }^{[16]}$ observed that UA exhibited anti-inflammatory activity in a mouse model by inhibiting and secretion of cytokines by $\mathrm{T}$ cells, $\mathrm{B}$ cells, and macrophages, through suppression of the transcription factors NF- $\kappa \mathrm{B}$, nuclear factor of activated $\mathrm{T}$ cells, and activator protein-1.

\section{Antitumor effect}

In a study, UA showed potential in the prevention and treatment of cancer by influencing several cell signaling enzymes and protecting against carcinogenic agents. ${ }^{[17]}$ The treatment of breast cancer cells with UA at low doses (5$20 \mu \mathrm{M})$ caused a G21 / G1 cell cycle arrest, an increase in p21 levels, oxidative stress, and DNA damage at $20 \mu \mathrm{M}$, UA induced autophagy and apoptosis of breast cancer cells without normal cell damage. ${ }^{[18]}$ Furthermore, UA enhanced phototoxicity of ultraviolet to visible light broadband radiation by modulating the activation of p53 and NF- $\kappa \mathrm{B}$ in melanoma cells. ${ }^{[19]}$

\section{Hepatoprotective effect}

The hepatoprotective effect of UA alone or in combination with other active ingredients on acute and chronic liver injury is well known. ${ }^{[20]}$ Gutierrez-Rebolledo et al. ${ }^{[21]}$ revealed that the subcutaneous administration of a mixture of UA and OA in male $\mathrm{BALB} / \mathrm{c}$ mice with hepatic injury induced by anti-tubercular agents resulted in a decrease in aspartate transaminase and alanine aminotransferase levels and improvement in histological alterations. UA inhibited the progression of non-alcoholic fatty liver disease, with a decrease in liver weight and hepatic steatosis, as well as accumulation of intracellular lipids, possibly due to an increase in lipid $\beta$-oxidation and inhibition of hepatic stress. $^{[22]}$

\section{Cardioprotective effect}

Cardiovascular disorders are one of the major causes of mortality and morbidity worldwide. UA is effective in the treatment of cardiovascular diseases. Liobikas et al. ${ }^{[23]}$ studied the effect of UA on mitochondria isolated from mouse heart, and investigated whether this compound induced the decoupling of oxidative phosphorylation in the mitochondria without affecting the respiration rate, besides inhibiting $\mathrm{H}_{2} \mathrm{O}_{2}$ production. In addition, the use UA in the treatment of myocardial fibrosis and hypertrophy in experimental models in vitro and in vivo showed the attenuation of fibrosis and cardiac hypertrophy, possibly through the inhibitory mechanism of the miR-21 / ERK signaling pathways in the myocardial cells. ${ }^{[24]}$

\section{Neuroprotective}

Some studies have shown the efficient neuroprotective effect of UA. It can regulate inflammatory responses in the ischemic brain of rats, which was indicated by a significant reduction in infarct size and a decrease in lipid peroxidation through the activation of the nuclear factor-erythroid 2related factor 2 (Nrf2). ${ }^{[25]}$ In the study performed by Ding et al., ${ }^{[26]}$ the use of UA for the treatment of brain lesions in a murine model significantly improved cerebral edema as well as neurological insufficiencies caused by trauma along with a decrease in oxidative stress. This study revealed that the neuroprotective effect of UA is associated with the activation of the Nrf2 pathway.

\section{Antimicrobial properties}

In a study by Singh et al. ${ }^{[27]}$ UA exhibited antimycobacterial activity against Mycobacterium smegmatis, Mycobacterium tuberculosis, and clinical isolates of multi-drug-resistant $M$. tuberculosis and, clinical isolates of multi-drug-resistant $M$. tuberculosis at a minimum inhibitory concentration (MIC) of $62.5 \mu \mathrm{g} / \mathrm{mL}$.

Nascimento et al. ${ }^{[28]}$ investigated the effect of UA and its derivatives on the susceptibility of certain pathogenic bacteria to antibiotics belonging to the aminoglycosides class (neomycin, amikacin, kanamycin and gentamicin). $3 \beta$-Formyloxy-urs12-en-28-oic acid $(64 \mu \mathrm{g} / \mathrm{mL})$ in combination with kanamycin showed a synergistic effect against $E$. coli, reducing MIC from $128 \mu \mathrm{g} / \mathrm{mL}$ to $8 \mu \mathrm{g} / \mathrm{mL}$.

\section{Antihyperlipidemic effect}

A few studies on the antihyperlipidemic effect of UA have been carried out. The use of UA and artesunate in the treatment of hyperlipidemia in rabbits revealed that the triglycerides were reduced by the two compounds individually. However, when used together, they significantly reduced cholesterol and triglyceride levels as well as hepatic steatosis and aortic root lesions. ${ }^{[29]}$

\section{Antidiabetic properties}

The antidiabetic property of UA was investigated in vivo experimental models for type 2 diabetes. The hepatic insulin resistance was improved by the modification of fatty acid, TNF- $\alpha$, and adiponectin levels, which enhanced PPAR $\alpha$ expression and consequently the regulation of PEPCK protein and phosphorylation of insulin receptor substrate-2. ${ }^{[30]}$ The antihyperglycemic effect of UA in hyperglycemic rats was mediated by insulin secretion and insulinomimetic effect on glucose uptake and synthesis and translocation of GLUT4. $^{[31]}$ 


\section{Antifungal}

In a study performed by Mahlo et al., ${ }^{[32]}$ UA with MIC of 20$250 \mathrm{mg} / \mathrm{mL}$ showed antifungal activity against Aspergillus niger, Aspergillus parasiticus, Colletotrichum gloeosporioides, Trichoderma harzianum, Penicillium expansum, Penicillium janthinellum and Fusarium oxysporum. At different concentrations (500, 750, and $1000 \mathrm{ppm})$, UA also significantly inhibited $(\mathrm{P}<$ 0.001) the spore germination of Alternaria alternata, Cochliobolus lunata, Fusarium moniliforme, Fusarium pallidoroseum, and Helminthosporium. ${ }^{[33]}$

\section{Anti-viral effect}

Zhao et al. ${ }^{[34]}$ evaluated the anti-viral effect of UA against cytomegalovirus in comparison to that of two other drugs, ganciclovir and jinyebaidu (control). They concluded that the antiviral activity of UA is significantly stronger than that of ganciclovir or jinyebaidu. In another study, UA presented anti-HCV (hepatitis $\mathrm{C}$ virus) effect through the suppression of HCV NS5B RdRp activity by acting as a noncompetitive inhibitor. ${ }^{[35]}$

\section{Trypanocidal effect}

UA exhibited in vitro trypanocidal effect as shown by an IC50 value of $25.5 \mu \mathrm{M}$ and $77 \%$ trypomastigote lysis at concentration at $128 \mu \mathrm{M}$. In the in vivo assay, the administration of UA at $20 \mathrm{mg} / \mathrm{kg} /$ day significantly reduced the parasitemia. ${ }^{[36]}$

\section{Drug delivery system}

UA exhibits various pharmacological effects. However, it has low solubility in aqueous medium $\left(1.02 \times 10^{-4} \mathrm{mg} / \mathrm{L}\right.$ at $\left.25^{\circ} \mathrm{C}\right)$ which affects its bioavailability and therapeutic application, because the solubility and polarity of a substance can influence its ability to penetrate biological membranes. ${ }^{[37,38]}$ Various strategies can be employed to overcome these limitations, such as particle size reduction, salt formation, chemical modifications of molecules, use of surfactants, $\mathrm{pH}$ adjustment or incorporation of the drug into different delivery systems. ${ }^{[39]}$ Drug delivery systems have been used with great success to improve the physicochemical properties of UA and favor its therapeutic application.

They also modulate drug release besides to improve solubility and increase the bioavailability of hydrophobic drugs. ${ }^{[40,41]}$ Several nanocarriers have been used for UA delivery, such as nanoemulsions, mesoporous silica nanoparticles, solid lipid nanoparticles, polymeric nanoparticles, liposomes, niossomal gels, and solid dispersions.

In a study performed by Li et al, ${ }^{[9]} \mathrm{pH}$-sensitive mesoporous silica nanoparticles were found to be biocompatible and allowed sustained release of UA, besides enhancing the cytotoxic effect against HepG2 human hepatocellular carcinoma cells, compared with free UA. Vargas de Oliveira et al. ${ }^{[8]}$ evaluated trypanocidal effect, cytotoxicity and in vitro dissolution profile of UA delivered by the nanoemulsions (constituted by purified water, Capryol ${ }^{\circledR} 90$ and Cremophor ${ }^{\circledR}$ EL/Transcutol ${ }^{\circledR}$ P) and investigated the improvement in the drug dissolution profile. UA release was found to be 3.75 times higher and
24 times faster than that from a physical mixture in alkaline dissolution medium, which indicated the importance of emulsification in enhancing the availability of the drug in the dissolution medium.

Nahak et al. ${ }^{[10]}$ investigated the physicochemical characteristics of the UA-loaded into solid lipid nanoparticles and found that the crystallinity of UA was lost due to its incorporation into the systems. In addition, the lipid matrix affected the rate of drug release and drug release pattern, exhibiting an antitumor effect greater than that of free UA against human leukemic cell line (K562) and melanoma cell line (B16). Long-circulating and $\mathrm{pH}$ sensitive liposomes containing UA (SpHL-UA) were used to improve the intravenous drug administration and its antitumoral effect on breast (MDA-MB-231) and prostate (LNCaP) cancer cell lines. ${ }^{[11]}$ In a study performed by Zhang et al., ${ }^{[42]}$ UA loaded nanoparticles using amphiphilic mPEGPCL block copolymers exhibited a sustained drug delivery profile and improve the antitumor effect of UA through the inhibition of COX-2 and activation of caspase- 3 in gastric tumor cells.

Topical formulations were also used owing to its advantages over the oral route, such as the absence of gastrointestinal effects, reduced renal toxicity, and greater patient compliance. ${ }^{[43,44]}$ Transdermal niossomal gels of UA developed for the treatment of arthritis resulted in a vesicle size of $665.45 \mathrm{~nm}$, drug incorporation efficiency of $92.74 \%$, and significantly superior in vivo compared with oral formulation and conventional gel system of UA. ${ }^{[12]}$

Solid dispersions can also be an interesting approach to the delivery of UA because these, comprise molecular mixtures of hydrophobic drugs with carriers that are hydrophilic or amphiphilic in nature, which in addition to allowing a reduction of drug particle size can improve the solubility and modulate drug release profile. ${ }^{[45]}$ An experiment performed by Eloy and Marchetti $^{[13]}$ to evaluate the influence of hydrophilic carriers (PEG 6000 and Poloxamer 407) and the method of preparation (fusion and solvent) of solid dispersions for aqueous solubility of UA showed that Poloxamer 407 increased the solubility and dissolution rate of the drug in solid dispersions more efficiently than PEG 6000 because of its surfactant properties. In addition, the solvent method for obtaining solid dispersions was more efficient than the fusion method for increasing drug solubility.

\section{Analytical methods}

The development and validation of analytical methods are important in the discovery phases, development, and manufacture of pharmaceuticals. Analytical method validation guarantees that the performance characteristics of the method employed are suitable for its intended use. ${ }^{[46]}$ With the introduction of new drug molecules, such as UA with no standards and analytical procedures in pharmacopeias, analytical method development and validation has become important.

Several analytical methods have been studied for qualitative and quantitative analyses of UA in various raw materials. Among most studied the analytical methods for the analysis of UA are HPLC, ${ }^{[4]}$ coupled gas chromatography-mass spectrometry (GC-MS), ${ }^{[4]}$ ultra-performance liquid chromatography (UPLC), ${ }^{[49]}$ cyclodextrin-modified micellar electrokinetic 


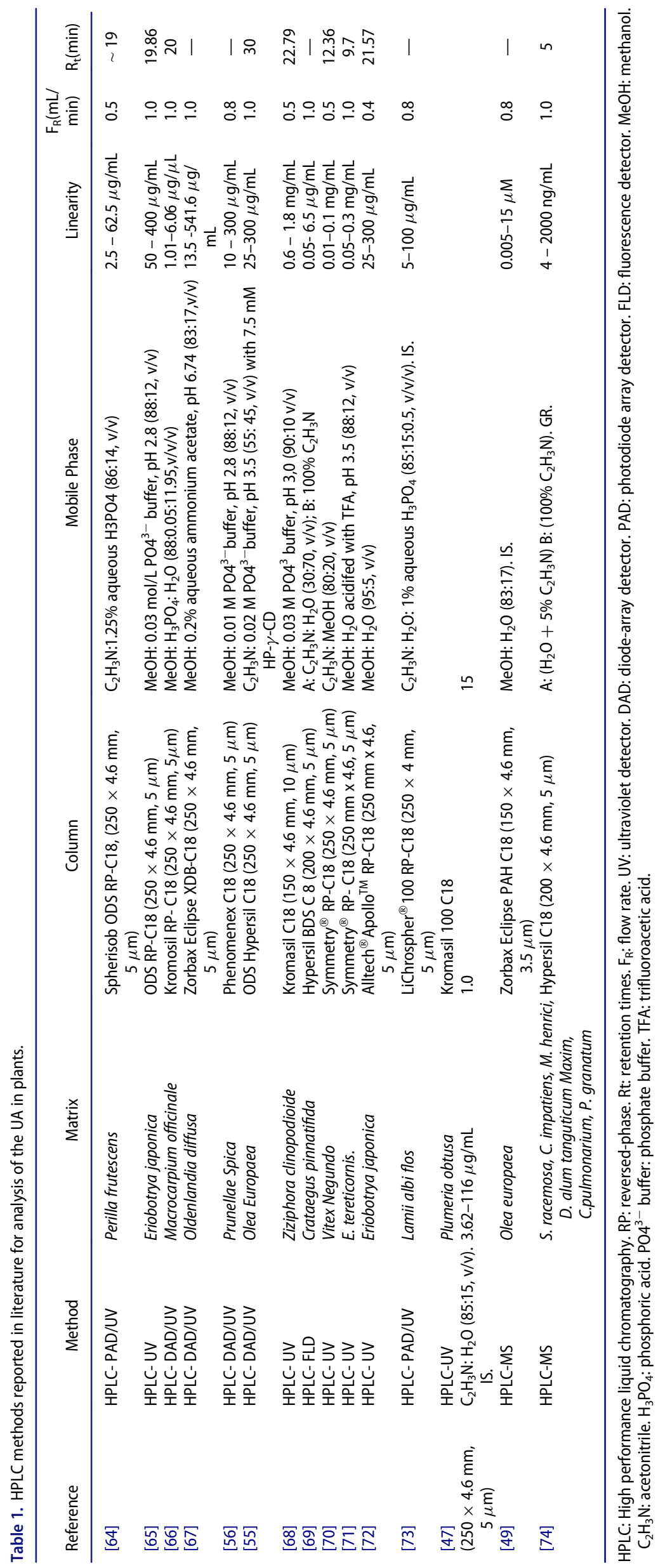


Table 2. HPLC methods reported in literature for analysis of the UA in biological fluids.

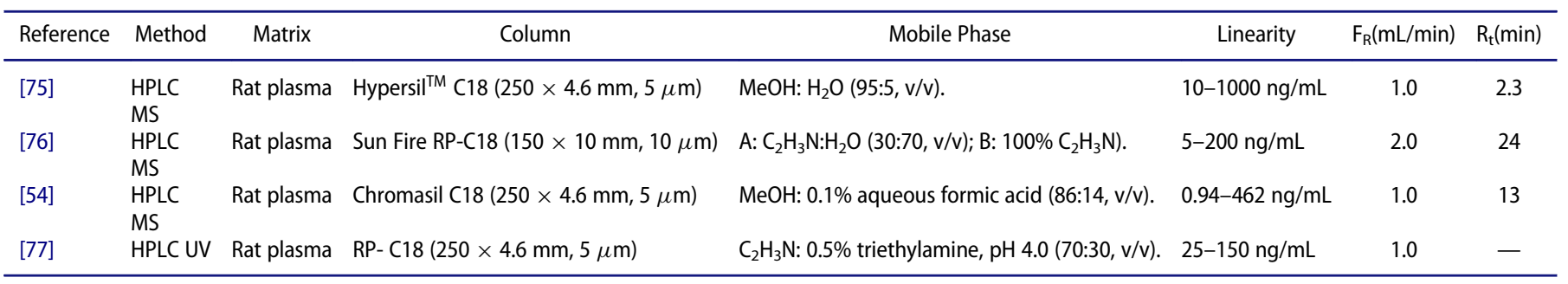

HPLC: High performance liquid chromatography. RP: reversed-phase. Rt: retention times. $\mathrm{F}_{\mathrm{R}}$ : flow rate. MS: Mass spectrometry. MeOH: methanol. $\mathrm{C}_{2} \mathrm{H}_{3} \mathrm{~N}$ : acetonitrile.

chromatography (CD-MEKC) ${ }^{[50]}$ micellar electrokinetic capillary chromatography (MECC), ${ }^{[51]}$ nonaqueous capillary electrophoresis (NACE), ${ }^{[52]}$ high performance thin layer chromatography (HPTLC); ${ }^{[53]} \mathrm{MS},{ }^{[54]}$ and nuclear magnetic resonance (NMR). ${ }^{[55]}$

Most of the analytical methods reported in the literature for the analysis of UA in different matrixes use the HPLC technique, possibly due of its simplicity, excellent sensitivity, resolution, and short analysis time. ${ }^{[56]}$ In addition, it is a widely used technique in the pharmaceutical industry for monitoring, evaluating and quality control of finished products despite the high operating cost. ${ }^{[57]}$

Most studies have reported UA separation by HPLC using C18 analytical columns and methanol-water or acetonitrilewater as the mobile phase with the $\mathrm{pH}$ adjusted between 2.8 and 6.74 using various organic additives (phosphate buffer, phosphoric acid, ammonium formate, formic acid, orthophosporic acid, and trifluoroacetic acid). The separation was conducted more frequently with isocratic elution than gradient elution. Retention times ranged from 2.3 to $30 \mathrm{~min}$ with a flow rate of $0.4-2 \mathrm{~mL} . \mathrm{min}^{-1}$. The HPLC methods reported in the literature for the analysis of UA in plants, biological fluids, and drug delivery systems have been presented in Tables 1, 2, and 3 .

Among coupled HPLC detectors used for UA analysis, the ultraviolet detector was the most common (200-215 nm). Diode array detector (DAD) and photodiode array detector (PAD) were also used as well as fluorometry (FLD) and MS. However, the accurate detection of this compound using absorptiometry has several challenges because UA lack chromophores, and exhibits low UV and fluorescence absorption. Furthermore, there are matrix interferences, such as in the case of plant samples, which have several substances with similar structures and polarities. ${ }^{[55,58]}$

Li et $a l^{[59]}$ reported an approach to increase the selectivity and sensitivity of UA and OA detection in medicinal herbs using a new dual-sensitive probe, 2-(5-benzoacridine)ethyl ptoluenesulfonate (BAETS), as a pre-column labeling reagent coupled with the HPLC-FLD method. Furthermore, an HPLCMS method developed to analyze pentacyclic triterpenes in Olea europaea $L$ showed improved sensitivity with a limit of quantification of $2 \mathrm{nM}$ for UA. ${ }^{[60]}$

Other hand, the other analytical methods were also used successfully to evaluate UA. An HPTLC method for the identification of UA and OA in the methanol extract of $W$. volubilis was investigated by Gopal et al. ${ }^{[61]}$ using a mixture of petroleum ether: chloroform: ethyl acetate: methanol (4:1:0.1:0.1) as mobile phase for UA. The method showed linearity at 10 $25 \mu \mathrm{g} / \mathrm{mL}$ and confirmed the presence of OA and UA in the methanol extract. Patel and Vyas ${ }^{[62]}$ studied the stability of UA under stress conditions (acid hydrolysis, alkaline hydrolysis, oxidation, photolysis, dry heat and humidity) and developed a stability indicating HPTLC method that enables separation of the drug from its main degradation products. The authors used pre-coated silica gel TLC plates and toluene: ethyl acetate: formic acid $(7: 3: 0.1, \mathrm{v} / \mathrm{v} / \mathrm{v})$ as the mobile phase. Densitometric detection and quantification $(530 \mathrm{~nm})$ showed linear relationship at $200-600 \mathrm{ng} / \mathrm{spot}$.

Caligiani et al. ${ }^{[48]}$ developed a GC-MS method for the determination of UA in commercial plant extracts. This technique was chosen due to its high selectivity and precision in the analysis of complex matrices. The method exhibited linearity in the 20$5000 \mathrm{mg} / \mathrm{kg}$ range, a limit of quantitation of $10 \mathrm{mg} / \mathrm{kg}$ (S/N ratio 10), and a limit of detection of $3 \mathrm{mg} / \mathrm{kg}$ ( $\mathrm{S} / \mathrm{N}$ ratio 3.3), indicating good flexibility in the analysis of several types of extracts.

A two-dimensional NMR method was compared with an HPLC method for the quantification OA and UA in plant extracts of the Lamiaceae and Oleaceae family. ${ }^{[55]}$ The current study showed that the use of proton-carbon heteronuclear single-quantum coherence (1H-13C HSQC) in combination with the proton-carbon heteronuclear multiple-bond correlation (1H-13C HMBC) NMR spectroscopy enables the bond of the proton and carbon-13 spins across the molecular backbone

Table 3. HPLC methods reported in literature for analysis of the UA in drug delivery systems.

\begin{tabular}{|c|c|c|c|c|c|c|c|}
\hline Reference & Method & Matrix & Column & Mobile Phase & Linearity & $\mathrm{F}_{\mathrm{R}}(\mathrm{mL} / \mathrm{min})$ & $\mathrm{R}_{\mathrm{t}}(\min )$ \\
\hline [78] & $\begin{array}{l}\text { HPLC } \\
\text { UV }\end{array}$ & Polymeric nanoparticles & $\mathrm{RP}-\mathrm{C} 18(250 \times 4 \mathrm{~mm} ; 5 \mu \mathrm{m})$ & MeOH: $0.1 \%$ aqueous $\mathrm{H}_{3} \mathrm{PO}_{4}(80: 12, \mathrm{v} / \mathrm{v})$. & $10-310 \mu \mathrm{g} / \mathrm{mL}$ & 1.0 & - \\
\hline [79] & $\begin{array}{l}\text { HPLC } \\
\text { UV }\end{array}$ & Solid dispersions & Lichrospher ${ }^{\circledR} \mathrm{RP}$ C18 $(250 \times 4$ mm; $5 \mu \mathrm{m})$ & $\mathrm{C}_{2} \mathrm{H}_{3} \mathrm{~N}: \mathrm{H}_{2} \mathrm{O}(88: 12, \mathrm{v} / \mathrm{v})$ & $1.0-50.0 \mu \mathrm{g} / \mathrm{mL}$ & 1.0 & 11 \\
\hline [11] & $\begin{array}{l}\text { HPLC } \\
\text { UV }\end{array}$ & Liposomes & LiChrosorb RP-C18 $(250 \times 4 \mathrm{~mm}, 5 \mu \mathrm{m})$ & $\mathrm{MeOH}: \mathrm{H}_{2} \mathrm{O}(1: 1, \mathrm{v} / \mathrm{v})$ & $5-60 \mu \mathrm{g} / \mathrm{mL}$ & 1.5 & - \\
\hline [80] & $\begin{array}{l}\text { HPLC } \\
\text { MS }\end{array}$ & Nanocrystals & Zorbax SB C18 $(4.6 \times 250 \mathrm{~mm}, 5 \mu \mathrm{m})$ & $\mathrm{C}_{2} \mathrm{H}_{3} \mathrm{~N}: 0.1 \%$ aqueous $\mathrm{H}_{3} \mathrm{PO}_{4}(85: 15, \mathrm{v} / \mathrm{v})$ & $7.8-2.0 \mathrm{ng} / \mathrm{mL}$ & 1.0 & - \\
\hline
\end{tabular}


promoting the identification these triterpenoids acid without the need for physicochemical separation and, thus allowing a rapid quantitative analysis ( $\sim 14 \mathrm{~min})$ and in accordance with the data obtained by HPLC.

Wang $^{[63]}$ investigated a near-infrared spectroscopy (NIRS) method for the quantitative analysis of OA and UA in Fructus ligustri lucidi. The proposed method was efficient as a comparative HPLC method as the values of the t-tests for NIRS and HPLC method were 0.590 and 0.441 , respectively both less than $\mathrm{t}(0.05,19) \frac{1}{4} 2.093$ with a $95 \%$ confidence level. Therefore, the results of the validation sets obtained by HPLC and NIRS presented no significant statistical difference.

Liu $^{[51]}$ studied an MECC method to determine UA and its isomer in Ligustrum lucidum using a buffer $(15 \mathrm{mmol} / \mathrm{L}$ disodium hydrogen phosphate, $15 \mathrm{mmol} / \mathrm{L}$ disodium tetreborate, $10 \mathrm{mmol} / \mathrm{L}$ SDS and 5\% v/v alcohol) UV detection at $214 \mathrm{~nm}$ at an applied voltage of $16 \mathrm{kV}$. An MEKC method developed by Yang ${ }^{[50]}$ for the determination and quantification of $\mathrm{OA}$ and UA in Pterocephalus hookeri using a buffer (50 mM borax, 10\% ethanol (v/v) and $\beta$ - cyclodextrin at $8 \mathrm{mM}, \mathrm{pH} 9.53)$ with an application voltage of $20 \mathrm{kV}$ and detection at $214 \mathrm{~nm}$ resulted in a good separation of OA and UA.

Nonaqueous capillary electrophoresis involves the use of electrolyte solutions obtained from pure organic solvents and allows the solubility and stability of hydrophobic substances. ${ }^{[52]}$ In a study performed by Qi et al., ${ }^{[52]}$ the NACE method was demonstrated to be suitable for simultaneous separation the UA and OA using a methanol:acetonitrile $(65: 35, \mathrm{v} / \mathrm{v})$ mixture containing $90 \mathrm{~mm}$ trishydroxymethylaminomethane (Tris) at an applied voltage of $+25 \mathrm{kV}$ and, UV detection at $214 \mathrm{~nm}$.

\section{Conclusion}

According to the studies presented in this review we can conclude that UA exhibits several biological effects, which indicate its potential in the treatment and prevention of various pathologies. In addition, different delivery systems for UA have been developed, such as nanoparticles and solid dispersions, which improve the biopharmaceutical properties of this molecule, favoring its therapeutic application.

The majority of presently applied methods for determining UA in plants use HPLC. With this review, we could verify that new methods are being introduced for UA analysis, which use other effective and accurate techniques as NMR. Furthermore, although most studies have reported the use of plants matrix for the development and validation of analytical methods for UA by HPLC, a few studies have evaluated this compound in biological fluids and drug delivery systems.

\section{Acknowledgments}

This work was supported by FAPESP (São Paulo, Brazil), CNPq (Brasília, Brazil), CAPES (Brasília, Brazil) and PACD-FCFAr-UNESP (Araraquara, Brazil).

\section{Funding}

Fundação de Amparo à Pesquisa do Estado de São Paulo (2016/22544-0).

\section{ORCID}

Andressa Maria Pironi (iD http://orcid.org/0000-0001-9387-3545

Patricia Rocha de Araújo (iD http://orcid.org/0000-0001-9048-6566

Hérida Regina Nunes Salgado (iD http://orcid.org/0000-0002-0385-340X

\section{References}

[1] Liu, J. Oleanolic acid and ursolic acid: Research perspectives. Journal of Ethnopharmacology. 2005, 92-94. DOI: 10.1016/j.jep.2005.05.024.

[2] Wozniak, Ł.; Skapska, S.; Marszałek, K. Ursolic Acid - A Pentacyclic Triterpenoid with a Wide Spectrum of Pharmacological Activities Ursolic Acid - A Pentacyclic Triterpenoid with a Wide Spectrum of Pharmacological Activities. Molecules. 2015, 20, 20614 20641 DOI: 10.3390/molecules201119721.

[3] Moreau, R. A.; Whitaker, B. D.; Hicks, K. B. Phytosterols, phytostanols, and their conjugates in foods: Structural diversity, quantitative analysis, and health-promoting uses. Progress in Lipid Research. 2002, pp 457-500. DOI: 10.1016/S0163-7827(02)00006-1

[4] Ebizuka, Y.; Katsube, Y.; Tsutsumi, T.; Kushiro, T.; Shibuya, M. Functional genomics approach to the study of triterpene biosynthesis. Pure Appl. Chem. 2003, 75 (August 2002), 369-374 DOI: 10.1351/pac200375020369.

[5] Babalola, I. T.; Shode, F. O. Ubiquitous Ursolic Acid: A Potential Pentacyclic Triterpene Natural Product. IC J. J. Pharmacogn. Phytochem. 2013, 8192 (2), 2668735-5.

[6] Kashyap, D.; Tuli, H. S.; Sharma, A. K. Ursolic acid (UA): A metabolite with promising therapeutic potential. Life Sci. 2016, 146, 201213 DOI: $10.1016 /$ j.lfs.2016.01.017.

[7] Eloy, J. O.; Saraiva, J.; De Albuquerque, S.; Marchetti, J. M.Preparation, characterization and evaluation of the in vivo trypanocidal activity of ursolic acid-loaded solid dispersion with poloxamer 407 and sodium caprate. Brazilian J. Pharm. Sci. 2015, 51 (1), 101-109. DOI: $10.1590 /$ S1984-82502015000100011.

[8] Vargas de Oliveira, E. C.; Carneiro, Z. A.; de Albuquerque, S.; Marchetti, J. M. Development and Evaluation of a Nanoemulsion Containing Ursolic Acid: a Promising Trypanocidal Agent. AAPS PharmSciTech 2017, 2003 (11), 9-12 DOI: 10.1208/s12249-017-0736-y.

[9] Li, T.; Chen, X.; Liu, Y.; Fan, L.; Lin, L.; Xu, Y.; Chen, S.; Shao, J. pHSensitive mesoporous silica nanoparticles anticancer prodrugs for sustained release of ursolic acid and the enhanced anti-cancer efficacy for hepatocellular carcinoma cancer. Eur. J. Pharm. Sci. 2017, 96, 456-463 DOI: 10.1016/j.ejps.2016.10.019.

[10] Nahak, P.; Karmakar, G.; Chettri, P.; Roy, B.; Guha, P.; Besra, S. E.; Soren, A.; Bykov, A. G.; Akentiev, A. V.; Noskov, B. A. et al.; Influence of lipid core material on physicochemical characteristics of an ursolic acid-loaded nanostructured lipid carrier: An attempt to enhance anticancer activity. Langmuir 2016, 32 (38), 9816-9825 DOI: 10.1021/acs.langmuir.6b02402.

[11] De Araújo Lopes, S. C.; Novais, M. V. M.; Teixeira, C. S.; HonoratoSampaio, K. S.; Perreira, M.; Ferreira, L. A. M.; Braga, F. C.; Oliveira, M. C. Preparation, physicochemical characterization, and cell viability evaluation of long-circulating and $\mathrm{pH}$-sensitive liposomes containing ursolic acid. Biomed Res. Int. 2013, 2013, 1-7. DOI: 10.1155/2013/467147.

[12] Jamal, M.; Imam, S. S.; Aqil, M.; Amir, M.; Mir, S. R.; Mujeeb, M. Transdermal potential and anti-arthritic efficacy of ursolic acid from niosomal gel systems. Int. Immunopharmacol. 2015, 29 (2), 361-369. DOI: $10.1016 /$ j.intimp.2015.10.029.

[13] Eloy, J. O.; Marchetti, J. M. Solid dispersions containing ursolic acid in Poloxamer 407 and PEG 6000: A comparative study of fusion and solvent methods. Powder Technol. 2014, 253, 98-106. DOI: 10.1016/ j.powtec.2013.11.017.

[14] Tuli, H. S.; Chaudhary, P.; Beniwal, V.; Sharma, A. K. Microbial pigments as natural color sources: current trends and future perspectives. J. Food Sci. Technol. 2015, 52 (8), 4669-4678 DOI: 10.1007/s13197-014-1601-6.

[15] Kim, S. H.; Hong, J. H.; Lee, Y. C. Ursolic acid, a potential PPAR $\gamma$ agonist, suppresses ovalbumin-induced airway inflammation and Penh by down-regulating IL-5, IL-13, and IL-17 in a mouse model of allergic asthma. Eur. J. Pharmacol. 2013, 701 (1-3), 131-143. DOI: 10.1016/j.ejphar.2012.11.033. 
[16] Checker, R.; Sandur, S. K.; Sharma, D.; Patwardhan, R. S.; Jayakumar, S.; Kohli, V.; Sethi, G.; Aggarwal, B. B.; Sainis, K. B. Potent antiinflammatory activity of ursolic acid, a triterpenoid antioxidant, is mediated through suppression of NF- $\kappa \mathrm{B}, \mathrm{AP}-1$ and NF-AT. PLoS One. 2012, 7 (2), 1-15. DOI: 10.1371/journal.pone.0031318.

[17] Zheng, Q.Y.; Li, P.P.; Jin, F.S.; Yao, C.; Zhang, G.H.; Zang, T.; Ai, X. Ursolic acid induces ER stress response to activate ASK1-JNK signaling and induce apoptosis in human bladder cancer T24 cells. Cell Signal. 2013, 25, 206-213. DOI: 10.1016/j.cellsig.2012.09.012.

[18] Lewinska, A.; Adamczyk-Grochala, J.; Kwasniewicz, E.; Deregowska, A.; Wnuk, M. Ursolic acid-mediated changes in glycolytic pathway promote cytotoxic autophagy and apoptosis in phenotypically different breast cancer cells. Apoptosis. 2017, 22 (6), 800-815. DOI: 10.1007/s10495-017-1353-7.

[19] Lee, Y. H.; Wang, E.; Kumar, N.; Glickman, R. D. Ursolic acid differentially modulates apoptosis in skin melanoma and retinal pigment epithelial cells exposed to UV-VIS broadband radiation. Apoptosis 2014, 19 (5), 816-828. DOI: 10.1007/s10495-013-0962-Z.

[20] Lin, C. N.; Gan, K. H. Antihepatotoxic principles of Solanum capsicastrum. Planta Med. 1989, 55 (1), 48-50. DOI: 10.1055/s-2006-961823.

[21] Gutiérrez-Rebolledo, G. A.; Siordia-Reyes, A. G.; Meckes-Fischer, M.; Jiménez-Arellanes, A. Hepatoprotective properties of oleanolic and ursolic acids in antitubercular drug-induced liver damage. Asian Pac. J. Trop. Med. 2016, 9 (7), 644-651. DOI: 10.1016/j.apjtm.2016.05.015.

[22] Li, J.-S.; Wang, W.-J.; Sun, Y.; Zhang, Y.-H.; Zheng, L. Ursolic acid inhibits the development of nonalcoholic fatty liver disease by attenuating endoplasmic reticulum stress. Food Funct. 2015, 6 (5), 16431651. DOI: $10.1039 / \mathrm{c} 5$ fo00083a.

[23] Liobikas, J.; Majiene, D.; Trumbeckaite, S.; Kursvietiene, L.; Masteikova, R.; Kopustinskiene, D. M.; Savickas, A.; Bernatoniene, J. Uncoupling and antioxidant effects of ursolic acid in isolated rat heart mitochondria. J. Nat. Prod. 2011, 74 (7), 1640-1644. DOI: 10.1021/np200060p.

[24] Dong, X.; Liu, S.; Zhang, L.; Yu, S.; Huo, L.; Qile, M.; Liu, L.; Yang, B.; $\mathrm{Yu}, \mathrm{J}$. Downregulation of miR-21 is Involved in Direct Actions of Ursolic Acid on the Heart: Implications for Cardiac Fibrosis and Hypertrophy. Cardiovasc. Ther. 2015, 33 (4), 161-167. DOI: 10.1111/ 1755-5922.12125.

[25] Li, L.; Zhang, X.; Cui, L.; Wang, L.; Liu, H.; Ji, H.; Du, Y. Ursolic acid promotes the neuroprotection by activating Nrf2 pathway after cerebral ischemia in mice. Brain Res. 2013, 1497, 32-39. DOI: 10.1016/j. brainres.2012.12.032.

[26] Ding, H.; Wang, H.; Zhu, L.; Wei, W. Ursolic Acid Ameliorates Early Brain Injury After Experimental Traumatic Brain Injury in Mice by Activating the Nrf2 Pathway. Neurochem. Res. 2017, 42 (2), 337-346. DOI: 10.1007/s11064-016-2077-8.

[27] Singh, A.; Venugopala, K. N.; Khedr, M. A.; Pillay, M.; Nwaeze, K. U.; Coovadia, Y.; Shode, F.; Odhav, B. Antimycobacterial, docking and molecular dynamic studies of pentacyclic triterpenes from Buddleja saligna leaves. J. Biomol. Struct. Dyn. 2016, 1102, 1-11. DOI: 10.1080/07391102.2016.1227725.

[28] do Nascimento, P.; Lemos, T; Bizerra, A.; Arriaga, Â.; Ferreira, D.; Santiago, G.; Braz-Filho, R.; Costa, J. Antibacterial and Antioxidant Activities of Ursolic Acid and Derivatives. Molecules 2014, 19 (1), 1317-1327. DOI: 10.3390/molecules 19011317.

[29] Wang, Y. L.; Wang, Z. J.; Shen, H. L.; Yin, M.; Tang, K. X. Effects of artesunate and ursolic acid on hyperlipidemia and its complications in rabbit. Eur. J. Pharm. Sci. 2013, 50 (3-4), 366-371. DOI: 10.1016/ j.ejps.2013.08.003.

[30] Wang, L.; Wang, G. L.; Liu, J. H.; Li, D.; Zhu, D. Z.; Wu, L. N. Effects of ursolic acid in ameliorating insulin resistance in liver of KKAy mice via peroxisome proliferator-activated receptors $\alpha$ and $\gamma$. J. Chinese Integr. Med. 2012, 10 (7), 793-799. DOI: 10.3736/jcim20120710.

[31] Castro, A. J. G.; Frederico, M. J. S.; Cazarolli, L. H.; Mendes, C. P.; Bretanha, L. C.; Schmidt, E, C.; Bouzon, Z. L.; Pinto, V. A. M.; Ramos, C. F.; Pizzolatti, M. G.; Silva, F. R. M. B. The mechanism of action of ursolic acid as insulin secretagogue and insulinomimetic is mediated by crosstalk between calcium and kinases to regulate glucose balance. Biochim. Biophys. Acta 2015, 1850 (1), 51-61. DOI: 10.1016/j.bbagen.2014.10.001.
[32] Mahlo, S. M.; McGaw, L. J.; Eloff, J. N. Antifungal activity and cytotoxicity of isolated compounds from leaves of Breonadia salicina. J. Ethnopharmacol. 2013, 148 (3), 909-913. DOI: 10.1016/j.jep.2013.05.041.

[33] Shaik, A. B.; Ahil, S. B.; Govardhanam, R.; Senthi, M.; Khan, R.; Sojitra, R.; Kumar, S.; Srinivas, A. Antifungal Effect and Protective Role of Ursolic Acid and Three Phenolic Derivatives in the Management of Sorghum Grain Mold Under Field Conditions. Chem. Biodivers. 2016, 13 (9), 1158-1164. DOI: 10.1002/cbdv.201500515.

[34] Zhao, J.; Chen, J.; Liu, T.; Fang, J.; Wan, J.; Zhao, J.; Li, W.; Liu, J.; Zhao, X.; Chen, S. Anti-viral effects of urosolic acid on guinea pig cytomegalovirus in vitro. J Huazhong Univ Sci Technol. Med Sci 2012, 32 (6), 883-887. DOI: 10.1007/s11596-012-1052-0.

[35] Kong, L.; Li, S.; Liao, Q.; Zhang, Y.; Sun, R.; Zhu, X.; Zhang, Q.; Wang, J.; Wu, X.; Fang, X., et al. Oleanolic acid and ursolic acid: Novel hepatitis $\mathrm{C}$ virus antivirals that inhibit NS5B activity. Antiviral Res. 2013, 98 (1), 44-53. DOI: 10.1016/j.antiviral.2013.02.003.

[36] Da Silva Ferreira, D.; Esperandim, V. R.; Toldo, M. P. A.; Saraiva, J.; Cunha, W. R.; De Albuquerque, S. Trypanocidal activity and acute toxicity assessment of triterpene acids. Parasitol. Res. 2010, 106 (4), 985-989. DOI: 10.1007/s00436-010-1740-2.

[37] US EPA, Estimation Program Interface (EPI) Suite. Ver. 4.0. Jan, 2009. http://www.epa.gov/oppt/exposure/pubs/episuitedl.htm apud PubChem. Open Chemistry Database. https://pubchem.ncbi.nlm.nih. gov/compound/Ursolic_acid\#section=Top.

[38] Shazly, G. A.; Ibrahim, M. A.; Badran, M. M.; Zoheir, K. M. A. Utilizing pluronic F-127 and gelucire 50/13 solid dispersions for enhanced skin delivery of flufenamic acid. Drug Dev. Res. 2012, 73 (6), 299307. DOI: $10.1002 / \mathrm{ddr} .21013$.

[39] Maulvi, F. A.; Dalwadi, S. J.; Thakkar, V. T.; Soni, T. G.; Gohel, M. C.; Gandhi, T. R. Improvement of dissolution rate of aceclofenac by solid dispersion technique. Powder Technol. 2011; 207 (1-3), 47-54. DOI: 10.1016/j.powtec.2010.10.009.

[40] He, Q.; Guo, S.; Qian, Z.; Chen, X. Development of individualized anti-metastasis strategies by engineering nanomedicines. Chem. Soc. Rev. 2015, 44 (17), 6258-6286. DOI: 10.1039/C4CS00511B.

[41] Khadka, P.; Ro, J.; Kim, H.; Kim, I.; Kim; J. T.; Kim, H.; Cho, J. M.; Yun, G.; Lee, J. Pharmaceutical particle technologies: An approach to improve drug solubility, dissolution and bioavailability. Asian Journal of Pharmaceutical Sciences. 2014, 9 (6), 304-316. DOI: https:// doi.org/10.1016/j.ajps.2014.05.005.

[42] Zhang, H.; Li, X.; Ding, J.; Xu, H.; Dai, X.; Hou, Z.; Zhang, K.; Sun, K.; Sun, W. Delivery of ursolic acid (UA) in polymeric nanoparticles effectively promotes the apoptosis of gastric cancer cells through enhanced inhibition of cyclooxygenase 2 (COX-2). Int. J. Pharm. 2013, 441 (1-2), 261-268. DOI:10.1016/j.ijpharm.2012.11.034.

[43] Osmani, R. A.; Aloorkar, N. H.; Kulkarni, A. S.; Harkare, B. R.; Bhosale; R. R. A new cornucopia in topical drug delivery: microsponge technology. Asian J. Pharm. Sci. Technol. 2014, 4 (1), 48-60.

[44] Baricevic, D.; Sosa, S.; Della Loggia, R.; Tubaro, A.; Simonovska, B.; Krasna, A.; Zupancic, A. Topical anti-inflammatory activity of Salvia officinalis L. leaves: the relevance of ursolic acid. J. Ethnopharmacol. 2001, 75 (2-3), 125-132. DOI: 10.1016/S0378-8741(00)00396-2.

[45] Vasconcelos, T.; Sarmento, B.; Costa, P. Solid Dispersions as Strategy to Improve Oral Bioavailability of Poor Water Soluble Drugs. Drug Discov. Today 2007, 12 (1), 23-24. DOI: 10.1016/j.drudis.2007.09.005.

[46] Bhagyasree, T.; Neelam, I.; Ajitha, A. U. M. R. V. A review on analytical method development and validation. Int. J. Pharmacutical Recearch Anal. 2014, 4 (8), 444-448.

[47] Alvarado, H. L.; Abrego, G.; Garduño-Ramirez, M. L.; Clares, B.; García, M. L.; Calpena, A. C. Development and validation of a highperformance liquid chromatography method for the quantification of ursolic/oleanic acids mixture isolated from Plumeria obtusa. $J$. Chromatogr. B Anal. Technol. Biomed. Life Sci. 2015, 983-984, 111116.DOI: 10.1016/j.jchromb.2015.01.009.

[48] Caligiani, A.; Malavasi, G.; Palla, G.; Marseglia, A.; Tognolini, M.; Bruni, R. A simple GC-MS method for the screening of betulinic, corosolic, maslinic, oleanolic and ursolic acid contents in commercial botanicals used as food supplement ingredients. Food Chem. 2013 , 136 (2), 735-741. DOI: 10.1016/j.foodchem.2012.08.011. 
[49] Giménez, E.; Juan, M. E.; Calvo-Melià, S.; Planas, J. M. A sensitive liquid chromatography-mass spectrometry method for the simultaneus determination in plasma of pentacyclic triterpens of Olea europaea L. Food Chem. 2017, 229, 534-541. DOI: 10.1016/j. foodchem.2017.02.116.

[50] Yang, P.; Li, Y.; Liu, X.; Jiang, S. Determination of free isomeric oleanolic acid and ursolic acid in Pterocephalus hookeri by capillary zone electrophoresis. J. Pharm. Biomed. Anal. 2007, 43 (4), 1331-1334. DOI: 10.1016/j.jpba.2006.10.042.

[51] Liu, H.; Shi, Y.; Wang, D.; Yang, G.; Yu, A.; Zhang, H. MECC determination of oleanolic acid and ursolic acid isomers in Ligustrum lucidum Ait. J. Pharm. Biomed. Anal. 2003, 32 (3), 479-485. DOI: 10.1016/S0731-7085(03)00235-8.

[52] Qi, S.; Ding, L.; Tian, K.; Chen, X.; Hu, Z. Novel and simple nonaqueous capillary electrophoresis separation and determination bioactive triterpenes in Chinese herbs. J. Pharm. Biomed. Anal. 2006, 40 (1), 35-41. DOI: 10.1016/j.jpba.2005.06.003.

[53] Kartini; Piyaviriyakul, S.; Siripong, P.; Vallisuta, O. HPTLC simultaneous quantification of triterpene acids for quality control of Plantago major L. and evaluation of their cytotoxic and antioxidant activities.Ind. Crops Prod. 2014, 60, 239-246. DOI: 10.1016/j. indcrop.2014.06.020.

[54] Zhao, L.; Li, W.; Li, Y.; Xu, H.; Lv, L.; Wang, X.; Chai, Y.; Zhang, G. Simultaneous Determination of Oleanolic and Ursolic Acids in Rat Plasma by HPLC - MS: Application to a Pharmacokinetic Study After Oral Administration of Different Combinations of QingGanSanJie Decoction Extracts. J Chromatogr Sci. 2015, 53 (7), 11851192. DOI: $10.1093 /$ chromsci/bmu217.

[55] Kontogianni, V. G.; Exarchou, V.; Troganis, A.; Gerothanassis, I. P. Rapid and novel discrimination and quantification of oleanolic and ursolic acids in complex plant extracts using two-dimensional nuclear magnetic resonance spectroscopy-Comparison with HPLC methods. Anal. Chim. Acta 2009, 635 (2), 188-195. DOI: 10.1016/j. aca.2009.01.021.

[56] Lee, M. K.; Ahn, Y. M.; Lee, K. R.; Jung, J. H.; Jung, O. S.; Hong, J. Development of a validated liquid chromatographic method for the quality control of Prunellae Spica: Determination of triterpenic acids. Anal. Chim. Acta 2009, 633 (2), 271-277. DOI: 10.1016/j.aca.2008.12.038.

[57] Rodríguez, M. P.; Pezza, H. R.; Pezza, L. Simple and clean determination of tetracyclines by flow injection analysis. Spectrochim. Acta Part A Mol. Biomol. Spectrosc. 2016, 153, 386-392. DOI: 10.1016/j. saa.2015.08.048.

[58] Wei, M. C.; Yang, Y. C.; Hong, S. J. Determination of oleanolic and ursolic acids in Hedyotis diffusa using hyphenated ultrasoundassisted supercritical carbon dioxide extraction and chromatography. Evidence-Based Complement. Altern. Med. 2015, 2015 (1). DOI: $10.1155 / 2015 / 450547$.

[59] Li, G.; Zhang, X.; You, J.; Song, C.; Sun, Z.; Xia, L.; Suo, Y. Highly sensitive and selective pre-column derivatization high-performance liquid chromatography approach for rapid determination of triterpenes oleanolic and ursolic acids and application to Swertia species: Optimization of triterpenic acids extraction an. Anal. Chim. Acta 2011, 688 (2), 208-218. DOI: 10.1016/j.aca.2011.01.010.

[60] Giménez, E.; Juan, M. E.; Calvo-Melià, S.; Barbosa, J.; Sanz-Nebot, V.; Planas, J. M. Pentacyclic triterpene in Olea europaea L: A simultaneous determination by high-performance liquid chromatography coupled to mass spectrometry. J. Chromatogr. A 2015, 1410, 68-75. DOI: 10.1016/j.chroma.2015.07.064.

[61] Gopal, V.; Mandal, V.; Mandal, S. C. HPTLC evaluation of oleanolic acid and ursolic acid from the methanol extract of Wattakaka volubilis. J. Acute Dis. 2014, 3 (1), 59-61. DOI: 10.1016/S2221-6189(14)60013-5.

[62] Patel, M. A.; Vyas, N. Development and validation of stability indicating HPTLC method for estimation of Ursolic acid. Asian J. Research Chem. 6(6), 141-152, 546-551.

[63] Wang, S.; Luo, L.; Li, Y.; Cai, R.; Zhao, W. Analytical Methods Qualitative and quantitative analysis of e ff ective components in Fructus Ligustri Lucidi by near infrared. 2013, 0-4. DOI: 10.1039/ c3ay40190a.

[64] Chen, J. H.; Xia, Z. H.; Tan, R. X. High-performance liquid chromatographic analysis of bioactive triterpenes in Perilla frutescens. J.
Pharm. Biomed. Anal. 2003; 32 (6), 1175-1179. DOI: 10.1016/ S0731-7085(03)00160-2.

[65] Zhou, C.; Chen, K.; Sun, C.; Chen, Q.; Zhang, W.; Li, X. Determination of oleanolic acid, ursolic acid and amygdalin in the flower of Eriobotrya japonica Lindl. by HPLC. Biomed. Chromatogr. 2007, 21, 755-761. DOI: 10.1002/bmc.817.

[66] Wang, H.; Wang, Z.; Guo, W. Comparative determination of ursolic acid and oleanolic acid of Macrocarpium officinalis (Sieb. et Zucc.) Nakai by RP-HPLC. Ind. Crops Prod. 2008, 28 (3), 328-332. DOI: 10.1016/j.indcrop.2008.03.004.

[67] Liang, Z.; Jiang, Z.; Fong, D. W.; Zhao, Z. Determination of oleanolic acid and ursolic acid in Oldenlandia diffusa and its substitute using high performance liquid chromatography. J. Food Drug Anal. 2009, 17 (2), 69-77.

[68] Tian, S.; Shi, Y.; Yu, Q.; Upur, H. Determination of oleanolic acid and ursolic acid contents in Ziziphora clinopodioides Lam. by HPLC method. Pharmacogn. Mag. 2010, 6 (22), 116-119 DOI: 10.4103/ 0973-1296.62898.

[69] Li, G. L.; You, J. M.; Song, C. H.; Xia, L.; Zheng, J.; Suo, Y. R. Development of a new HPLC method with precolumn fluorescent derivatization for rapid, selective and sensitive detection of triterpenic acids in fruits. J. Agric. Food Chem. 2011, 59 (7), 2972-2979. DOI: 10.1021/jf104224t.

[70] Taralkar, S. V.; Chattopadhyay, S. A HPLC Method for Determination of Ursolic Acid and Betulinic Acids from their Methanolic Extracts of Vitex negundo Linn. J. Anal. Bioanal. Tech. 2012, 3 (3), 1-6 DOI: 10.4172/2155-9872.1000134.

[71] Maurya, A.; Srivastava, S. K. Determination of ursolic acid and ursolic acid lactone in the leaves of Eucalyptus tereticornis by HPLC. J. Braz. Chem. Soc. 2012, 23 (3), 468-472 DOI: 10.1590/ S0103-50532012000300013.

[72] Xu, X. H.; Su, Q.; Zang, Z. H. Simultaneous determination of oleanolic acid and ursolic acid by RP-HPLC in the leaves of Eriobotrya japonica Lindl. J. Pharm. Anal. 2012, 2 (3), 238-240 DOI: 10.1016/j. jpha.2012.01.006.

[73] Wójciak-Kosior, M.; Sowa, I.; Kocjan, R.; Nowak, R. Effect of different extraction techniques on quantification of oleanolic and ursolic acid in Lamii albi flos. Ind. Crops Prod. 2013, 44, 373-377 DOI: 10.1016/j.indcrop.2012.11.018

[74] Wu, H.; Li, G.; Liu, S.; Liu, D.; Chen, G.; Hu, N.; Suo, Y.; You, J. Simultaneous determination of six triterpenic acids in some Chinese medicinal herbs using ultrasound-assisted dispersive liquid-liquid microextraction and high-performance liquid chromatography with fluorescence detection. J. Pharm. Biomed. Anal. 2015, 107, 98-107 DOI: 10.1016/j.jpba.2014.10.031.

[75] Liao, Q.; Yang, W.; Jia, Y.; Chen, X.; Gao, Q.; Bi, K. LC-MS determination and pharmacokinetic studies of ursolic acid in rat plasma after administration of the traditional chinese medicinal preparation $\mathrm{Lu}-$ Ying extract. Yakugaku Zasshi 2005, 125 (6), 509-515 DOI: 10.1248/ yakushi.125.509.

[76] Chen, G.; Li, J.; Song, C.; Suo, Y.; You, J. A sensitive and efficient method for simultaneous trace detection and identification of triterpene acids and its application to pharmacokinetic study. Talanta 2012, 98, 101-111 DOI: 10.1016/j.talanta.2012.06.053.

[77] Muralidharan, S.; Vijayan, V. Simple and Effective HPLC Method Development and its Valida- tion for Ursolic acid in Drug Free plasma: Application to bio-analytical studies. 2016, 2 (3), 52-55. DOI: 10.5530/PTB.2016.2.8.

[78] Almeida, M. M.; Bou-Chacra, N. A.; Tavares, V. F.; Baby, A. R.; Kaneko, T. M.; Velasco, M. V. R. Determination of Ursolic Acid from Polymeric Nanoparticles using High-Performance Liquid Chromatography Method. Lat. Am. J. Pharm. 2012, 31 (8), 1187-1221.

[79] Oliveira Eloy, J.; De Oliveira, E. C. V.; Marotta-Oliveira, S. S. A.; Saraiva, J.; Marchetti, J. M. Desenvolvimento e validaçãoo de um método analítico por CLAE para quantificão de ácido ursólico em dispersões sólidas. Quim. Nova 2012, 35 (5), 1036-1040.

[80] Song, J.; Wang, Y.; Song, Y.; Chan, H.; Bi, C.; Yang, X.; Yan, R.; Wang, Y.; Zheng, Y. Development and Characterisation of Ursolic Acid Nanocrystals Without Stabiliser Having Improved Dissolution Rate and In Vitro Anticancer Activity. AAPS PharmSciTech 2014, 15 (1), 11-19 DOI: 10.1208/s12249-013-0028-0. 